\title{
Assessment and management of acute asthma in the elderly : a comparison with younger asthmatics
}

\author{
IAN S. PeTHERAM \\ M.B., M.R.C.P.
}

\author{
D. A. JONES \\ M.B., M.R.C.P.
}

\author{
J. V. Collins \\ M.D., M.R.C.P. \\ Brompton Hospital, Fulham Road, London, SW3 $6 H P$
}

\begin{abstract}
Summary
Assessment on admission and responses to treatment were studied in 20 patients aged 65 years or over admitted with severe acute exacerbations of asthma and were compared with patients aged 40 years or less who were managed similarly. The elderly asthmatic had less marked tachycardia and pulsus paradoxus compared to the younger group for similar degrees of airways obstruction and arterial blood gas abnormalities. Assessment confined to physical examination would, therefore, have underestimated the severity of their asthma. The rates of improvement in airflow obstruction were similar in both young and old but those elderly patients who had required maintenance oral corticosteroids were less likely to reach their predicted peak expiratory flow rate (PEFR) than their peers or younger patients.
\end{abstract}

\section{Introduction}

The prevalence of asthma in the elderly is about $6.5 \%$ (Burr et al., 1979) and attention has been drawn to the difficulty of diagnosis in this age group. The symptoms of chronic bronchitis may co-exist and patients may lack evidence of atopy or exerciseinduced bronchospasm which assist diagnosis in younger patients (Lee and Stretton, 1972). Asthma developing later in life tends to produce chronic daily symptoms and often needs corticosteroids for optimum control. On a background of chronic respiratory symptoms these patients may also suffer sudden severe exacerbations which have been considered to have a poor prognosis (Unger, 1956) and may cause death as rapidly as in younger patients (McDonald, Seaton and Williams, 1976). The authors studied 20 patients aged 65 years or over, admitted consecutively, to find whether severe attacks differed clinically or by laboratory assessment from attacks in 87 patients aged 40 years or less, admitted during the same period, and to com- pare the response of airways obstruction of each group to an intensive regime of treatment.

\section{Patients and methods}

Patients were considered to have asthma if peak expiratory flow rate (PEFR) or forced expiratory volume in one second $\left(\mathrm{FEV}_{1}\right)$ changed by $20 \%$ or more either spontaneously or as a result of treatment. Patients who had clinical, radiological or physiological features of chronic bronchitis, emphysema, bronchiectasis or broncho-pulmonary aspergillosis were excluded. On admission the duration of history of asthma, length of present exacerbation and use of corticosteroids in the previous year was noted. The severity of exacerbation was assessed by examination of heart rate, pulsus paradoxus (Knowles and Clark, 1973) and arterial blood gas analysis. Airflow obstruction was measured by PEFR and dry spirometry (Vitalograph).

All subjects received inhaled salbutamol via a nebulizer or intermittent positive pressure breathing every $4 \mathrm{hr}$, and an intravenous (i.v.) infusion containing aminophylline $500 \mathrm{mg}$, 8-hourly, and hydrocortisone $200 \mathrm{mg}$ 6-hourly. Oral prednisolone, initially $30-60 \mathrm{mg} / \mathrm{day}$, with reduction in dosage as recovery progressed was given to all patients and oxygen, antibiotics and physiotherapy were given as indicated.

The response of airflow obstruction was monitored by recording PEFR every $4 \mathrm{hr}$ and improvement was assessed as (a) initial response by the change in PEFR $4 \mathrm{hr}$ after starting treatment. This was assessed as a percentage of PEFR obtained on admission; (b) time taken to reach half eventual improvement in PEFR; (c) time taken to reach maximum PEFR; (d) incidence and severity of diurnal variation (morning fall of PEFR expressed as a percentage of the highest value of the previous day). 
TABLE 1. Assessment of elderly and younger groups

\begin{tabular}{lcccccccccc}
\hline Group & $n$ & M & F & Atopic & Oral steroids & History of & \multicolumn{3}{c}{ Period of deterioration (days) } & Respiratory \\
asthma $>10$ years & $<3$ & $3-7$ & $7-14$ & $>14$ \\
infection
\end{tabular}

The degree of reversibility for each patient was defined as the best recorded PEFR expressed as a percentage of predicted PEFR. Mean values of continuous variables were compared by $t$ tests and discontinuous variables by $\chi^{2}$ tests.

\section{Results}

\section{Assessment on admission (Table 1)}

The period of deterioration before admission tended to be longer in the older patients. Thirteen $(65 \%)$ elderly patients had worsening symptoms for more than 14 days before admission compared with $29 \%$ of the younger group $(0.01<P<0.02)$. There was no difference in clinical evidence of respiratory tract infection between the two groups. The younger group had suffered from asthma for longer $(P<$ $0.05)$, contained more atopic subjects $(P<0.001)$ and fewer who were taking maintenance oral corticosteroids $(P<0.01)$. The older patients had lower mean heart rates $(P<0.01)$ and less pulsus paradoxus $(P<0.02)$ than the younger group (Table 2) but there was no difference in arterial blood gas tensions nor in the severity of airways obstruction between the groups although mean forced vital capacity (FVC) was lower in the older group $(P<0.05)$.

\section{Response to treatment}

Four hours after starting treatment the mean increase in PEFR recorded on admission was $80 \%$ for the elderly group compared with $73 \%$ in the younger group (not significant). After $24 \mathrm{hr}$ of treatment, $50 \%$ of the older patients had achieved at least half their eventual improvement in PEFR, whereas $75 \%$ of the younger patients had reached this point of their recovery but the difference was not statistically significant. The percentage number of patients of each group who had reached maximum PEFR were not significantly different by $24 \mathrm{hr}$, by 1 week or by the end of 2 weeks. The group mean
PEFR finally achieved in the elderly group (74\% predicted) was significantly lower than the mean s PEFR in younger patients $(91 \%$ predicted $)(P<\vec{\circ}$ $0.002)$. The mean reversibility of 7 elderly patients $\overrightarrow{\vec{H}}$ who were not taking maintenance corticosteroids $\stackrel{\sigma}{\sigma}$ was $85 \%$ of predicted compared to $68 \%$ of predicted for the 13 who were. Thirty per cent. of the $\exists$ patients in both groups had severe diurnal variation if in PEFR ( $>50 \%$ fall) that started most commonly between the third and fifth day of treatment.

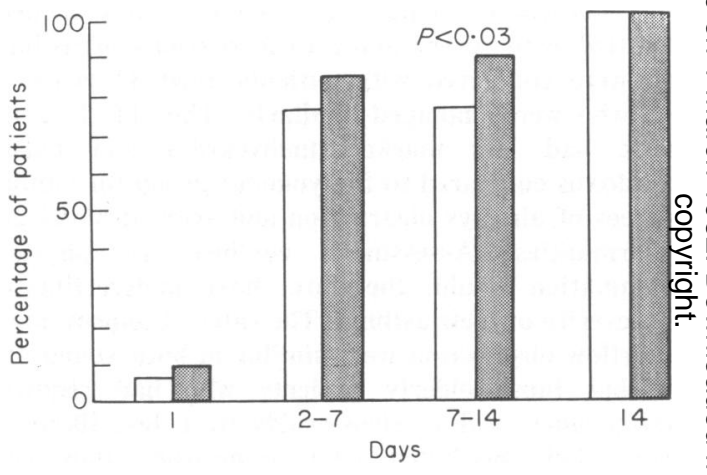

FIG. 1. Percentage of patients amongst elderly $(\square)$ and younger (*) asthmatics achieving maximum improvement in PEFR (peak expiratory flow rate) over a 2 -week period.

No patient in either group had side effects from corticosteroids that required modification of the treatment regimen.

\section{Discussion}

This study has shown that elderly asthmatic 을 patients may suffer severe acute exacerbations of $D$ their disease (status asthmaticus) which have been well described in young and middle-aged patients. Airways obstruction and abnormalities of blood gas

TABLE 2. Mean values ( \pm 1 s.d.) of measurements made on admission

\begin{tabular}{|c|c|c|c|c|c|c|c|c|}
\hline Group & $n$ & $\begin{array}{c}\text { Heart rate } \\
\text { (beats/min) }\end{array}$ & $\begin{array}{l}\text { Paradox } \\
(\mathrm{mmHg})\end{array}$ & $\begin{array}{l}\text { PEFR } \\
(1 / \mathrm{min})\end{array}$ & $\begin{array}{l}\mathrm{Pa}, \mathrm{O}_{2} \\
(\mathrm{kPa})\end{array}$ & $\underset{(\mathrm{kPa})}{\mathrm{Pa}, \mathrm{CO}_{2}}$ & $\underset{\text { (l) }}{\mathrm{FEV}_{1}}$ & $\begin{array}{c}\text { FVC } \\
\text { (l) }\end{array}$ \\
\hline $\begin{array}{l}\text { Elderly } \\
<40 \text { years }\end{array}$ & $\begin{array}{l}20 \\
87\end{array}$ & $\begin{array}{c}96.1( \pm 16.7) \\
P<0.01 \\
110.4( \pm 18.6)\end{array}$ & $\begin{array}{c}11 \cdot 2( \pm 10 \cdot 5) \\
P<0.02 \\
18 \cdot 4( \pm 12 \cdot 1)\end{array}$ & $\begin{array}{l}95( \pm 44) \\
112( \pm 45)\end{array}$ & $\begin{array}{l}8.45( \pm 1.51) \\
8.30( \pm 1.95)\end{array}$ & $\begin{array}{l}5.27( \pm 0.99) \\
4.75( \pm 1.25)\end{array}$ & $\begin{array}{l}0.52( \pm 0.27) \\
0.73( \pm 0.30)\end{array}$ & $\begin{array}{c}0.98( \pm 0.52) \\
P<0.05 \\
1.42( \pm 0.61)\end{array}$ \\
\hline
\end{tabular}


tensions were as severe in the elderly group as in younger patients. Unless these measurements had been made, the true severity of attack would have been underestimated since heart rate and pulsus paradoxus, physical signs which are reliable guides to severity in younger patients (Knowles and Clark, 1973; Rees, Miller and Donald, 1968), were less marked in the elderly patients. Young asthmatics tend to have a faster heart rate during exacerbations of asthma compared with older patients (Cooke, Crompton and Grant, 1979). In normal people, with advancing age, reduction in static lung volumes and decrease in gas transfer (Muiesan, Sorbini and Grassi, 1971) with increase in ventilation-perfusion inequality (Holland et al., 1968) and closing volume (Leblanc, Ruff and Milic-Emili, 1970) combine to produce hypoxaemia (Sorbini et al., 1968). Cardiovascular responses to hypoxaemia also diminish with age (Kronenberg and Drage, 1973) and this may explain why heart rate and pulsus paradoxus are less helpful signs in asthma in the elderly. Patients in the elderly group tended to deteriorate for longer periods before admission than the younger patients.

The present results show that in elderly asthmatic patients airways obstruction can improve at similar rates to those of young patients when treated with a combination of i.v. and inhaled bronchodilators and i.v. and oral corticosteroids. By four hours, before a detectable response to oral corticosteroids occurs, both groups of patients had shown improvement in airflow of the same degree. Afterwards the elderly group continued to show marked improvement in PEFR although they were slightly slower to recover than the younger group. The elderly patients were less likely to reach predicted PEFR after intensive treatment, particularly if they had been taking long-term maintenance corticosteroids which perhaps may indicate that the airways changes are less reversible in the elderly. Excessive diurnal variation has been correlated with the risk of sudden death in asthma (Hetzel, Clark and Branthwaite, 1977) and was as common in the older group as in the younger patients. The exact cause is unknown but since effective treatment is available its detection is important.
In elderly patients who complain of continuous or intermittent breathlessness the cause should not be assumed to be fixed obstructive airways disease. All should have formal assessment of reversibility including a course of corticosteroids. Objective evidence of improvement can be obtained with a peak flow meter. When these patients develop acute life-threatening exacerbations they should be managed as vigorously as younger patients. The data show that Unger's previous gloomy prognosis for severe asthma in the elderly (Unger, 1956) may no longer be tenable.

\section{References}

Burr, M.L., Charles, T.J., Roy, K. \& Seaton, A. (1979) Asthma in the elderly: an epidemiological survey. British Medical Journal, 1, 1041.

Cooke, N.J., Crompton, G.K. \& Grant, I.W.B. (1979) Observations on the management of acute bronchial asthma. British Journal of Diseases of the Chest, 73, 157.

Hetzel, M.R., Clark, T.J.H. \& Branthwaite, M.A. (1977) Asthma: analysis of sudden deaths and ventilatory arrests in hospital. British Medical Journal, 1, 808.

Holland, J., Milic-Emili, J., Markham, P.T. \& Bates, D.V. (1968) Regional distribution of pulmonary ventilation and perfusion in the elderly. Journal of Clinical Investigations, 47, 81.

Knowles, G.K. \& Clark, T.J.H. (1973) Pulsus paradoxus as a valuable sign indicating severity of asthma. Lancet, ii, 1356.

Kronenberg, R.S. \& Drage, C.W. (1973) Attenuation of the ventilatory and heart rate response to hypoxia and hypercapnia with ageing in normal men. Journal of Clinical Investigation, 52, 1812.

Leblanc, P., Ruff, F. \& Milic-Emili, J. (1970) Effects of age and body position on 'airway closure' in man. Journal of Applied Physiology, 28, 448.

LeE, H. \& Stretton, T.B. (1972) Asthma in the elderly. British Medical Journal, 4, 93.

McDonald, J.B., Seaton, A. \& Williams, D.A. (1976) Asthma deaths in Cardiff 1963-74; 90 deaths outside hospital. British Medical Journal, 1, 1493.

Muiesan, G., Sorbini, C.A. \& Grassi, V. (1971) Respiratory function in the aged. Bulletin of Physiopathology of Respiration, 7, 973.

Rees, H.A., Miller, J.S. \& Donald, K.W. (1968) A study of the clinical course and arterial blood has tensions of patients in status asthmaticus. Quarterly Journal of Medicine, 37, 541.

Sorbini, C.A., Brassi, V., Soluias, E \& Muiesan, G. (1968) Arterial oxygen tension in relation to age in healthy subjects. Respiration, $25,2$.

UNGER, L. (1956) Chronic bronchial asthma in the older age group. Medical Clinics of North America, 40, 115. 